Maria Clara Ferreira de Miranda

\title{
Gestão Democrática da Cidade e Plano Diretor: o Caso-Referência da Cidade de Rio das Ostras
}

\author{
DissertaçÃo de MESTRAdo
}

DEPARTAMENTO DE DIREITO

Programa de Pós-Graduação em Teoria Geral do Estado e Direito Constitucional

Rio de Janeiro

Março de 2006 


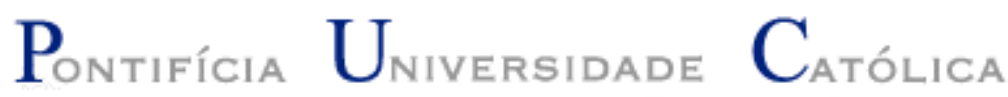

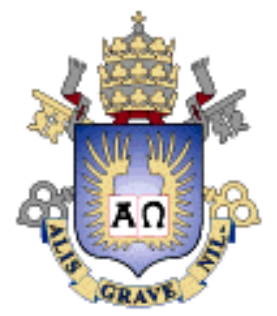

Maria Clara Ferreira de Miranda

\author{
Gestão Democrática da Cidade e \\ Plano Diretor: o Caso-Referência da \\ Cidade de Rio das Ostras
}

Dissertação de Mestrado

Dissertação apresentada como requisito parcial para a obtenção do grau de Mestre pelo Programa de Pós-Graduação em Teoria Geral do Estado e Direito Constitucional do Departamento de Direito da PUC-Rio.

Orientador: Prof. Rosangela Lunardelli Cavallazzi

Rio de Janeiro

Março de 2006 


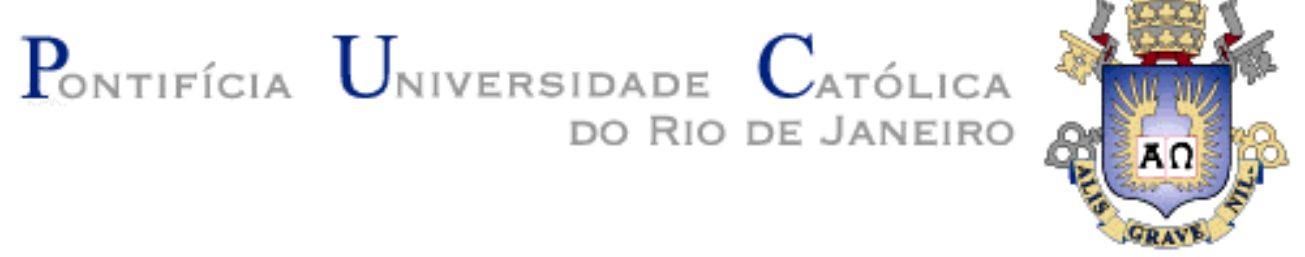

Maria Clara Ferreira de Miranda

\author{
Gestão Democrática da Cidade e \\ Plano Diretor: o Caso-Referência da \\ Cidade de Rio das Ostras
}

Dissertação apresentada como requisito parcial para a obtenção do grau de Mestre pelo Programa de Pós-Graduação em Teoria Geral do Estado e Direito Constitucional do Departamento de Direito da PUC-Rio. Aprovada pela Comissão Examinadora abaixo assinada.

Prof. Rosangela Lunardelli Cavallazzi Orientador Departamento de Direito - PUC-Rio

Prof. João Ricardo Dornelles Departamento de Direito - PUC-Rio

Prof. Antônio Cavalcanti Maia Departamento de Direito - PUC-Rio

Prof. Ronaldo do Livramento Coutinho Faculdade de Direito - UERJ/UFF

Prof. João Pontes Nogueira Vice-Decano de Pós-Graduação do Centro de Ciências Sociais - PUC-Rio

Rio de Janeiro, 08 de março de 2006 
Todos os direitos reservados. É proibida a reprodução total ou parcial do trabalho sem autorização da universidade, da autora e do orientador.

\section{Maria Clara Ferreira de Miranda}

Ficha catalográfica

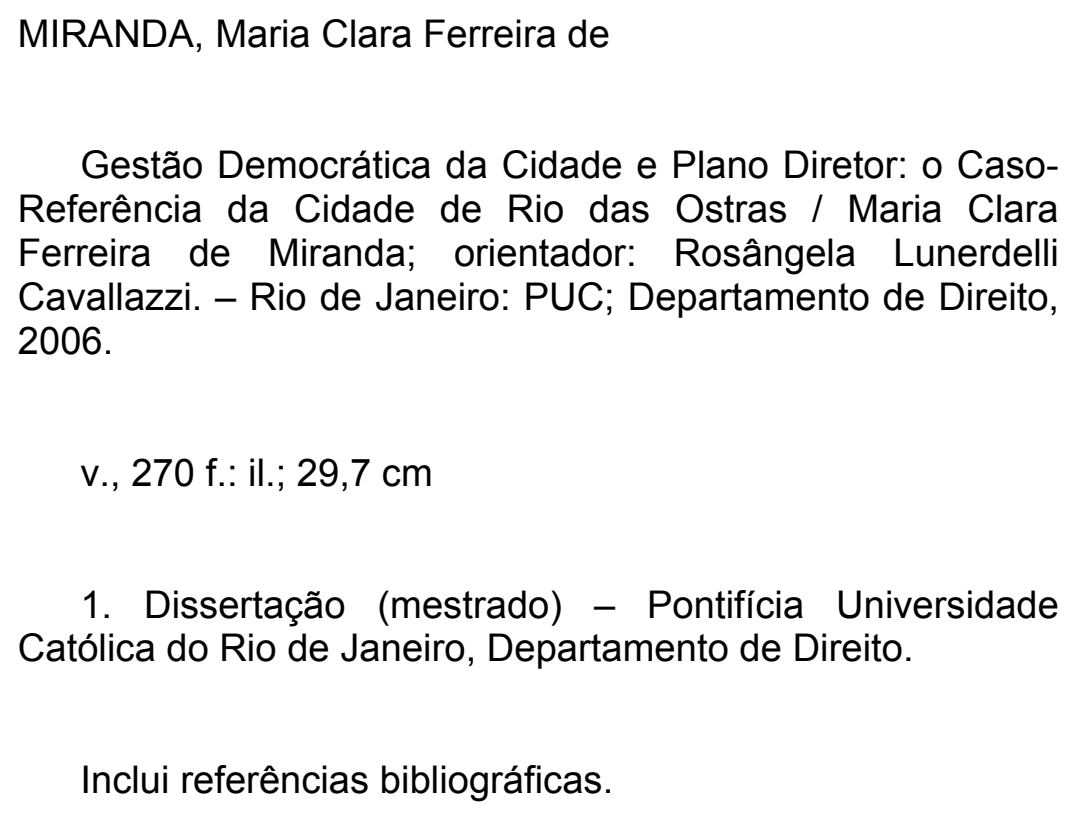

Gestão Democrática da Cidade e Plano Diretor: o CasoReferência da Cidade de Rio das Ostras / Maria Clara Ferreira de Miranda; orientador: Rosângela Lunerdelli Cavallazzi. - Rio de Janeiro: PUC; Departamento de Direito, 2006.

v., 270 f.: il.; $29,7 \mathrm{~cm}$

1. Dissertação (mestrado) - Pontifícia Universidade Católica do Rio de Janeiro, Departamento de Direito.

Inclui referências bibliográficas.

1. Direito - Teses. 2. Direito Constitucional. 3. Direito Urbanístico. 4. Gestão Democrática. 5. Participação Popular. 6. Rio das Ostras. Cavallazzi, Rosangela Lunardelli. II. Pontifícia Universidade Católica do Rio de Janeiro. Departamento de Direito. III. Título. 
Ao Augusto Henrique e a Mariana, meus filhos e "minha vida", fontes constante de alegria, inspiração e orgulho, meus símbolos de futuras gerações.

A quem dá sentido a tudo isso, Augusto, meu amor. 


\section{AGRADECIMENTOS}

Meus sinceros agradecimentos a todos aqueles que me ajudaram a crescer como pessoa e como profissional, e direta, ou indiretamente contribuíram neste trabalho:

Aos meus pais, Cátia e Ronaldo, por tudo.

À minha irmã Ciça e ao meu cunhado Flavio pelo carinho e apoio de sempre.

Às minhas amigas, Júlia Stella e Stefania, por sempre estarem me incentivando e discutindo comigo os assuntos desta Tese.

Ao Maurício Paraguassú Pinheiro, Secretário do Pro-Urbe de Rio das Ostras, pelo material disponibilizado para a Tese e pela sua simpatia ao me receber na Secretaria.

Ao Alcebíades Sabino, ex-prefeito de Rio das Ostras pelas informações prestadas sobre o Município de Rio das Ostras e sobre o Processo de Elaboração do Plano Diretor.

Aos colegas, funcionários e professores do Programa de Pós-Graduação em Teoria do Estado e Direito Constitucional da Puc-Rio, em especial a minha querida orientadora Rosângela Cavallazzi com quem partilhei alegrias, conquistas e frustrações na construção de um projeto acadêmico novo na área de Direito Urbanístico.

Ao CNPQ pelo auxílio concedido para esta pesquisa, através da Bolsa. 


\section{RESUMO}

Miranda, Maria Clara Ferreira de; Cavallazzi, Rosângela Lunardelli. Gestão Democrática da Cidade e Plano Diretor: o Caso-Referência da Cidade de Rio das Ostras Rio de Janeiro, 2006. 270p. Dissertação de Mestrado Departamento de Direito, Pontifícia Universidade Católica do Rio de Janeiro.

A dissertação intitulada Gestão Democrática da Cidade, Poder Local e Plano Diretor: O caso referência do Município de Rio das Ostras analisa o processo de gestão democrática na construção do conteúdo normativo do Plano Diretor destacando a tutela do direito à cidade no campo dos direitos humanos, à luz da teoria da ação comunicativa da Habermas. Entende-se que o termo "gestão democrática" enseja a participação dos cidadãos e habitantes nas funções de planejamento, controle e avaliação das políticas urbanas, sendo uma condição de realização do Plano Diretor conforme disciplinado pelo Estatuto da Cidade. A plena realização da gestão democrática é garantia fundamental de que os instrumentos de política urbana trazidos pelo Estatuto da Cidade não serão ferramentas a serviço de concepções tecnocráticas e excludentes, mas sim, instrumentos de promoção do direito à cidade para todos. Nesta dissertação tais premissas teóricas são validadas através de estudo de caso concreto que reporta a experiência de elaboração democrática do Projeto de Lei apresentado pelo Poder Executivo para instituir o Plano Diretor de Rio das Ostras Este trabalho é resultado de abordagem interdisciplinar e considera os princípios constitucionais e as diretrizes do Estatuto da Cidade pressupostos teórico-metodológicos para interpretação no processo de produção de sentido da norma urbanística.

\section{Palavras chaves:}

Direito Constitucional, Direito Urbanístico, democracia, direitos humanos, direito à cidade, plano diretor, participação popular, Rio das Ostras. 


\section{ABSTRACT}

Miranda, Maria Clara Ferreira de; Cavallazzi, Rosângela Lunardelli. The democratic administration of the city, local power and urban plan: the case of the city of Rio das Ostras Rio de Janeiro, 2006. 270p. MSc. Dissertation - Departamento de Direito, Pontifícia Universidade Católica do Rio de Janeiro.

The dissertation entitled "The democratic administration of the city, local power and urban plan: the case of the city of Rio das Ostras" focuses the process of the democratic administration in the process of constructing the rules categories of the urban plan law, pointing out the legal control of the cities' citizenship rights in the large field of the human rights, concerning the Habermas' communicative action theory. For "democratic administration" we understand the engagement of the citizens and inhabitants of the city in the activities of projection, control and valuation of the urban politics, which is a condition of the urban plan, ruled in the federal urban law - The "Estatuto da Cidade". The complete accomplishment of the democratic administration is a fundamental guarantee for protecting the Estatuto da Cidade of being a non desirable instrument of technical conceptions, giving it its real destination, which is to promote the city rights for all the citizens. In this dissertation, these theory suppositions are valid through a concrete study of case which refers to the experience of democratic elaboration of the propose of a law, presented by the Executive to institute the Rio das Ostras' Urban Plan. The present work is the result of an interdisciplinary approach and considers the constitutional principles and the mandatory provisions of the Estatuto da Cidade and its theory and methodological proposes, in the process of producing a real meaning for the urban rules.

\section{Key words:}

Constitutional Law, Urban Law, democracy, human rights, Urban Plan, public participation, Rio das Ostras. 


\section{SUMÁRIO}

1. Introdução 13

2 Direito Público e Direito Urbanístico 19

2.1. Cidade, Urbanismo e Democracia 19

2.1.1 O Direito Urbanístico 22

2.1.2 Estatuto da Cidade: diretrizes gerais e instrumentos de política urbana 26

2.1.3 Princípios de Direito Urbanístico 32

2.2. O Direito à Cidade como Direito Humano 46

2.2.1. Evolução Histórica dos Direitos Humanos 46

2.2.2. O Direito Humano à Cidade 53

3 Gestão Democrática da Cidade e Plano Diretor: o caso referência da Cidade de Rio das Ostras

3.1. Descrição do Município de Rio das Ostras 57

3.1.1 Histórico $\quad 57$

3.1.2 Caracterização do Município $\quad 58$

3.2. A Cidade e o Consenso: a Reconstrução Discursiva do Direito e da Democracia segundo Jürgen Habermas 63

3.2.1. A Participação Popular como Condição de Validade

do Plano Diretor 72

3.2.2. Pressupostos Jurídico-Constitucionais da Gestão Democrática da Cidade $\quad 75$

3.2.3. Conceito, Objetivos e Operacionalização dos Instrumentos 77

3.3. A Participação Popular na elaboração do Plano Diretor:

o Caso de Rio das Ostras. $\quad 80$

3.3.1. A Atividade das Comissões Temáticas. As Diretrizes Populares 83

3.3.1.1. Moradia 83

3.3.1.2. Educação $\quad 84$

$\begin{array}{ll}\text { 3.3.1.3 Saúde } & 88\end{array}$ 
3.3.1.4. Saneamento Básico 90

3.3.1.5. Turismo 92

3.3.1.6. Indicadores Sociais e Econômicos 94

3.3.1.7. Indicadores Orçamentários Financeiros 97

4. Conclusão: direito à cidade e à cidadania 101

5. Bibliografia 106

6. Anexos

I: Decreto que Institui Comissão de Assessoramento para Elaboração do Plano Diretor; Circular do Pro-Urbe e Pré Agenda do Cronograma de Elaboração do Plano Diretor.

II: Ofício do Senhor Secretário do Pro-Urbe Maurício Pinheiro para formação da Comissão; correspondências dos órgãos representativos da sociedade civil para o Secretário do Pro-Urbe.

III: Registro das Perguntas e Sugestões elaboradas por membros da sociedade civil durante os Seminários.

IV: Registro da Publicidade durante o processo de Elaboração do Plano Diretor.

V: Projeto Lei do Plano Diretor do Município de Rio das Ostras

VI: Acórdão do Tribunal de Justiça do Rio Grande do Sul. Ação Direta de Inconstitucionalidade $\mathrm{n}^{\mathrm{0}} 70003026564$. 


\section{Lista de figuras}

Figura 1 - Mapa das regiões de governo e micro regiões geográficas do Estado do Rio de Janeiro - 2003.

Figura 2- Mapa de rodovias e ferrovias que atravessam o município de Rio das Ostras.

Figura 3- Gráfico da distribuição da população no Estado do Rio de Janeiro.

Figura 4- Gráfico da distribuição da população na região das baixadas litorâneas.

Figura 5- Gráfico comparativo da distribuição da população no município de Rio das Ostras, na região das baixadas litorâneas e no Estado do Rio de Janeiro.

Figura 6- Gráfico de anos de estudo por população acima de 10 anos de idade no Estado do Rio de Janeiro e no município de Rio das Ostras. 85

Figura 7- Gráfico da evolução percentual da população analfabeta acima de 15 anos no município de Rio das Ostras.

Figura 8- Gráfico panorama do ensino fundamental no Estado do Rio de Janeiro e no município de Rio das Ostras.

Figura 9- Gráfico de concluintes do ensino fundamental no município de Rio das Ostras.

Figura 10- Gráfico panorama do ensino médio no Estado do Rio de Janeiro e no município de Rio das Ostras.

Figura 11- Gráfico de concluintes do ensino médio no município de Rio das Ostras.

Figura 12- Gráfico de unidades ambulatoriais no município de Rio das Ostras.

Figura 13- Gráfico dos recursos repassados pelo SUS para o município de Rio das Ostras.

Figura 14- Mapa das regiões turísticas do Estado do Rio de Janeiro.

Figura 15- Mapa da região turística costa do sol.

Figura 16- Gráfico da evolução comparativa do IDH no Estado do 
Figura 17- Gráfico da composição do PIB do município de Rio das Ostras em 2002.

Figura 18- Gráfico da evolução da receita realizada no período de 1998 a 2003 no município de Rio das Ostras.

Figura 19- Gráfico da evolução da despesa realizada no período de 1998 a 2003 no município de Rio das Ostras.

Figura 20- Gráficos da evolução das receitas correntes no período de 1998 a 2003 no município de Rio das Ostras.

Figura 21- Gráfico dos gastos por função no município de Rio das Ostras.

Figura 22- Gráfico das reduções, incrementos e constância na seqüência anual de composições de gastos das principais funções no município de Rio das Ostras. 
"A poesia da natureza é, exatamente, apenas uma construção do espírito. A cidade é uma imagem poderosa que aciona o nosso espírito. Por que a cidade não seria, ainda hoje, uma fonte de poesia?" Le Corbusier 